\title{
PRACTICAL SUPERCONDUCTOR DEVELOPMENT \\ FOR ELECTRICAL POWER APPLICATIONS \\ ARGONNE NATIONAL LABORATORY \\ QUARTERLY REPORT FOR THE PERIOD ENDING DECEMBER 31, 2003
}

This is a multiyear experimental research program that focuses on improving relevant material properties of high-critical temperature $\left(\mathrm{T}_{\mathcal{C}}\right)$ superconductors and developing fabrication methods that can be transferred to industry for production of commercial conductors. The development of teaming relationships through agreements with industrial partners is a key element of the Argonne National Laboratory (ANL) program.

\section{Technical Highlights}

We report significant improvement in the properties of $\mathrm{YBa}_{2} \mathrm{Cu}_{3} \mathrm{O}_{7-\mathrm{x}}(\mathrm{YBCO})$ films deposited on $\mathrm{SrRuO}_{3}(\mathrm{SRO})$-buffered substrates with an $\mathrm{MgO}$ film applied by inclined substrate deposition (ISD). Transport critical current density $\left(\mathrm{J}_{\mathrm{c}}\right)$ for these samples was increased to $6.2 \times 10^{5} \mathrm{~A} / \mathrm{cm}^{2}$ at $77 \mathrm{~K}$, from the values of $0.03-0.10 \times 10^{5} \mathrm{~A} / \mathrm{cm}^{2}$ that were initially reported. Raman spectroscopy studies indicated that the $\mathrm{YBCO}$ films were incompletely oxygenated, and that Raman analysis might be useful in evaluating the texture of SRO films. A three-dimensional (3-D) finite element analysis (FEA) of residual stresses in a multilayered coated conductor indicated that the interactions between layers are not significant; therefore, Stoney's equation [1] should be applicable to the measurement of residual stresses in complex, multilayered coated conductors.

\section{$\underline{\text { YBCO Films on } \mathrm{SrRuO}_{3} \text { (SRO)-Buffered ISD-MgO Substrates }}$}

The standard ISD architecture consists of $\mathrm{YBCO} / \mathrm{CeO}_{2} / \mathrm{YSZ} / \mathrm{HE}-\mathrm{MgO} / \mathrm{ISD}-$ $\mathrm{MgO} / \mathrm{YSZ} / \mathrm{HC}$, where ISD-MgO is the $\mathrm{MgO}$ layer made by ISD, HE-MgO is the homoepitaxial $\mathrm{MgO}$ layer that is subsequently deposited, YSZ is yttria-stabilized zirconia, and $\mathrm{HC}$ is the substrate, Hastelloy C-276. SRO, having a relatively small $(\approx 6.5 \%)$ lattice mismatch with $\mathrm{MgO}$ and a lattice mismatch with YBCO that is between that of YSZ and $\mathrm{CeO}_{2}$, might be a suitable alternative for one or both of the YSZ and $\mathrm{CeO}_{2}$ layers in this architecture. In addition, $\mathrm{SRO}$ has favorable thermal and electrical conductivity. For these reasons, we have been investigating SRO as a potential alternative buffer layer for coated conductors made by the ISD process.

We showed previously that $\mathrm{YBCO}$ on SRO-buffered ISD-MgO substrates had sharper in-plane alignment than did $\mathrm{YBCO}$ on $\mathrm{YSZ}$ - and $\mathrm{CeO}_{2}$-buffered ISD-MgO 
substrates [2]. Using pulsed laser deposition (PLD) to prepare YBCO films on SRObuffered $\mathrm{MgO}$ single-crystal substrates at deposition temperatures of $750-790^{\circ} \mathrm{C}$ [3], we showed that $\mathrm{YBCO}$ deposited at $770^{\circ} \mathrm{C}$ had the best superconducting properties (transport $\mathrm{J}_{\mathrm{c}}$ of $2.5 \mathrm{MA} / \mathrm{cm}^{2}$ and $\mathrm{T}_{\mathrm{c}}$ of $91 \mathrm{~K}$ ). Scanning electron microscopy (SEM) of the film deposited at $770^{\circ} \mathrm{C}$ revealed uniform and well-connected grains, and X-ray analysis showed that it had good in- and out-of-plane texture. During the past quarter, we extended our investigation of YBCO films deposited by PLD on SRO-buffered ISD-MgO metallic (HC) substrates, and we report here the superconducting and crystallographic properties of representative films.

To begin sample preparation, we deposited YSZ (thickness = $300 \AA$ ) on polished HC substrates at $700^{\circ} \mathrm{C}$ using electron beam evaporation. Using electron beam evaporation with an angle of $55^{\circ}$ between the substrate normal and the direction of evaporation, we then deposited the ISD-MgO layer at room temperature. The homoepitaxial $\mathrm{MgO}$ layer was deposited at $700^{\circ} \mathrm{C}$ by electron beam evaporation with the direction of evaporation normal to the substrate.

The SRO and YBCO layers were deposited by PLD. A KrF excimer laser (Lambda Physik, Compex 201) with a wavelength of $248 \mathrm{~nm}$ and pulse duration of $25 \mathrm{~ns}$ was focused onto a target rotating at $8 \mathrm{rpm}$. Both the YBCO and SRO targets (supplied by Praxair Surface Technology) were $2.54 \mathrm{~cm}$ in dia. and $0.63 \mathrm{~cm}$ thick. Laser beam energy of $128 \mathrm{~mJ} /$ pulse with a frequency of $4 \mathrm{~Hz}$ was used to fabricate SRO films; laser beam energy of $140 \mathrm{~mJ} /$ pulse with a frequency of $8 \mathrm{~Hz}$ was used for YBCO films. Prior to deposition of SRO, the $\mathrm{MgO}$ substrates were ultrasonically cleaned in acetone and then in methyl alcohol for $10 \mathrm{~min}$. They were then mounted on a substrate heater with the aid of silver paste. The distance between the substrate and target was $6.5 \mathrm{~cm}$. The SRO buffer layer (thickness $=100 \mathrm{~nm}$ ) was deposited by PLD on the ISD-MgO substrate at a temperature of $770^{\circ} \mathrm{C}$ and pressure of 50 mtorr $\mathrm{O}_{2}$. Finally, $\mathrm{YBCO}$ (thickness=300 nm) was deposited by PLD on the SRO layer at $770^{\circ} \mathrm{C}$ and $240 \mathrm{mtorr} \mathrm{O}_{2}$. After the deposition of $\mathrm{YBCO}$, the conductor was annealed at $450^{\circ} \mathrm{C}$ in oxygen at a pressure of 750 torr for $90 \mathrm{~min}$.

$X$-ray diffraction (XRD) pole-figure analysis was used to evaluate the texture of the $\mathrm{YBCO} / \mathrm{SRO} / \mathrm{HE}-\mathrm{MgO} / \mathrm{ISD}-\mathrm{MgO} / \mathrm{YSZ} / \mathrm{HC}$ structure. XRD $\phi$-scans were used to characterize the in-plane texture of the YBCO and SRO films, and the out-of-plane texture of $\mathrm{YBCO}$ was examined by $\omega$-scans. Figure 1 shows the pole figures for the YBCO (005), SRO (020), and $\mathrm{MgO}$ (002) planes. From the pole figures, we measured a value of $32^{\circ}$ for the tilt angle $(\beta)$ of $\mathrm{YBCO}, \mathrm{SRO}$, and $\mathrm{MgO}$, where $\beta$ is the angle between the (001) pole and normal to the substrate. 


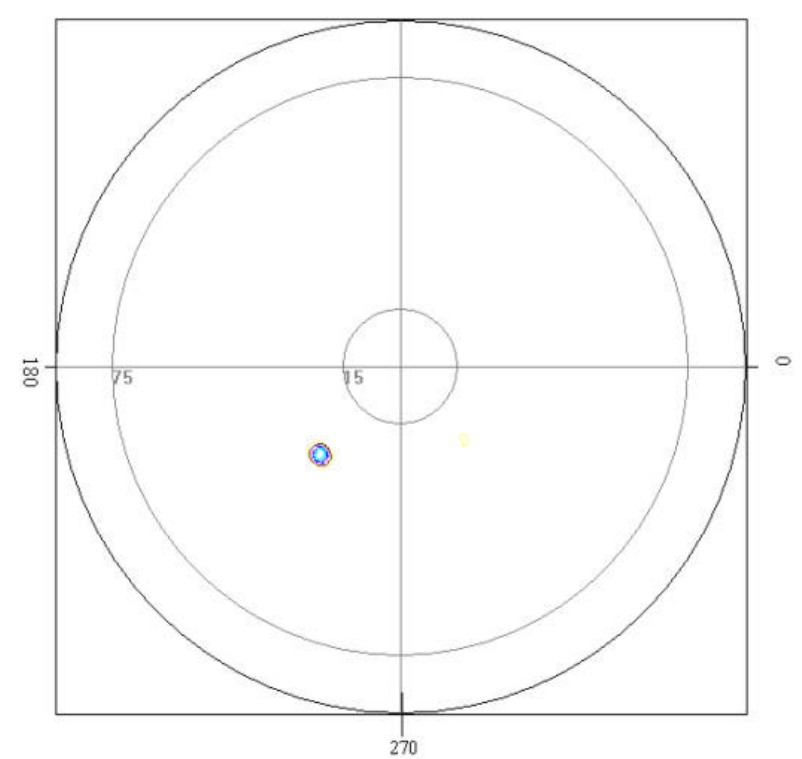

(a)

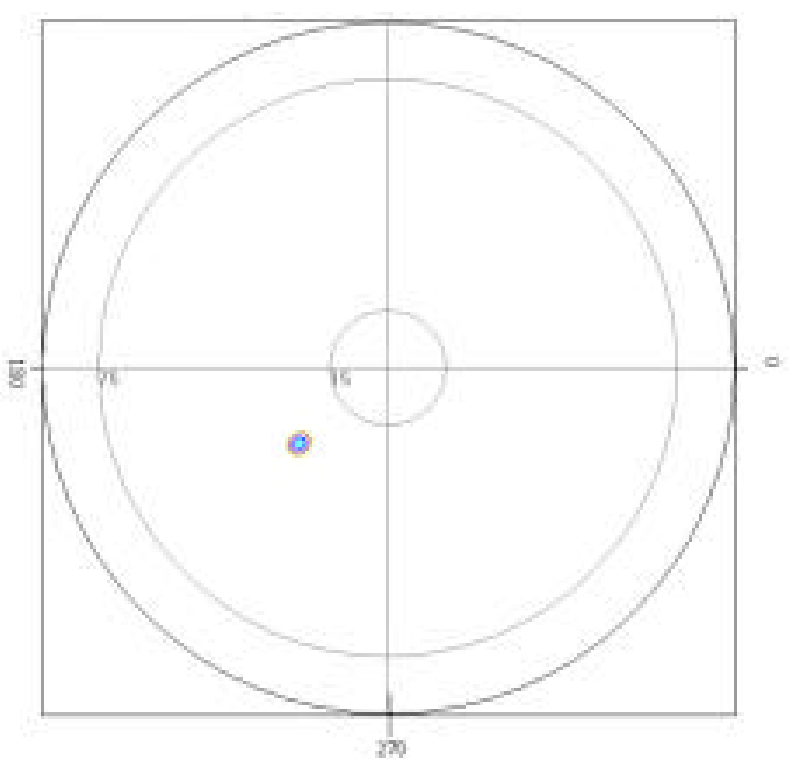

(b)

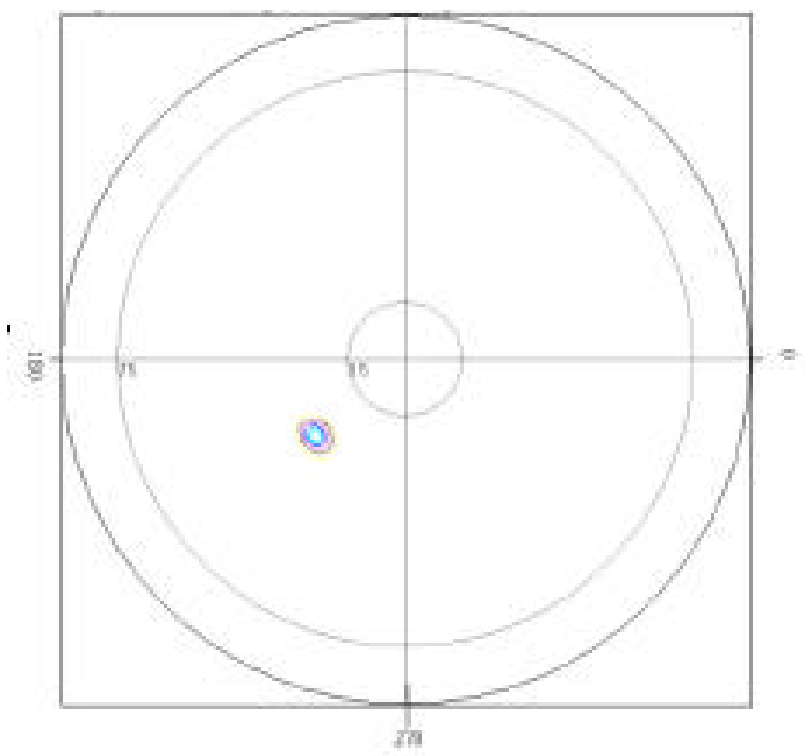

(c)

Fig. 1. Pole figures for (a) YBCO (005) plane, (b) SRO (020) plane, and (c) MgO (002) plane on HC substrate.

Figure 2 shows the YBCO (005), SRO (020), and $\mathrm{MgO}$ (002) peaks that were measured from YBCO/SRO/ISD-MgO/YSZ/HC along with their full-width-at-halfmaximum (FWHM) values. The YBCO (005) peak had an FWHM of $\approx 6.6^{\circ}$, while the SRO (020) peak had an FWHM of $7.05^{\circ}$, indicating good in-plane texture for both layers. The small value $\left(3.19^{\circ}\right)$ for the FWHM of the YBCO (007) $\omega$-scan (Fig. 3) showed that the YBCO film also had good out-of-plane texture. 


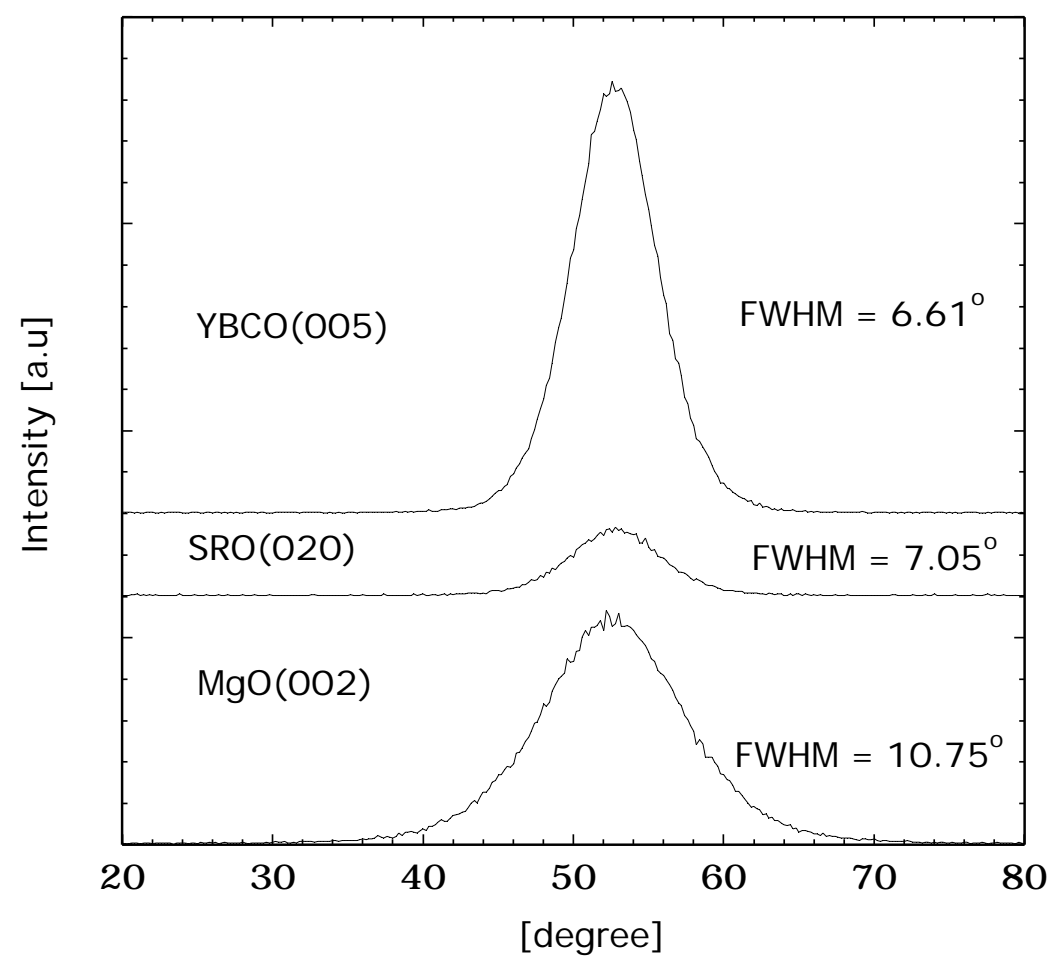

Fig. 2. X-ray $\phi$-scan of YBCO (005), SRO (020), and MgO (002) crystalline planes.

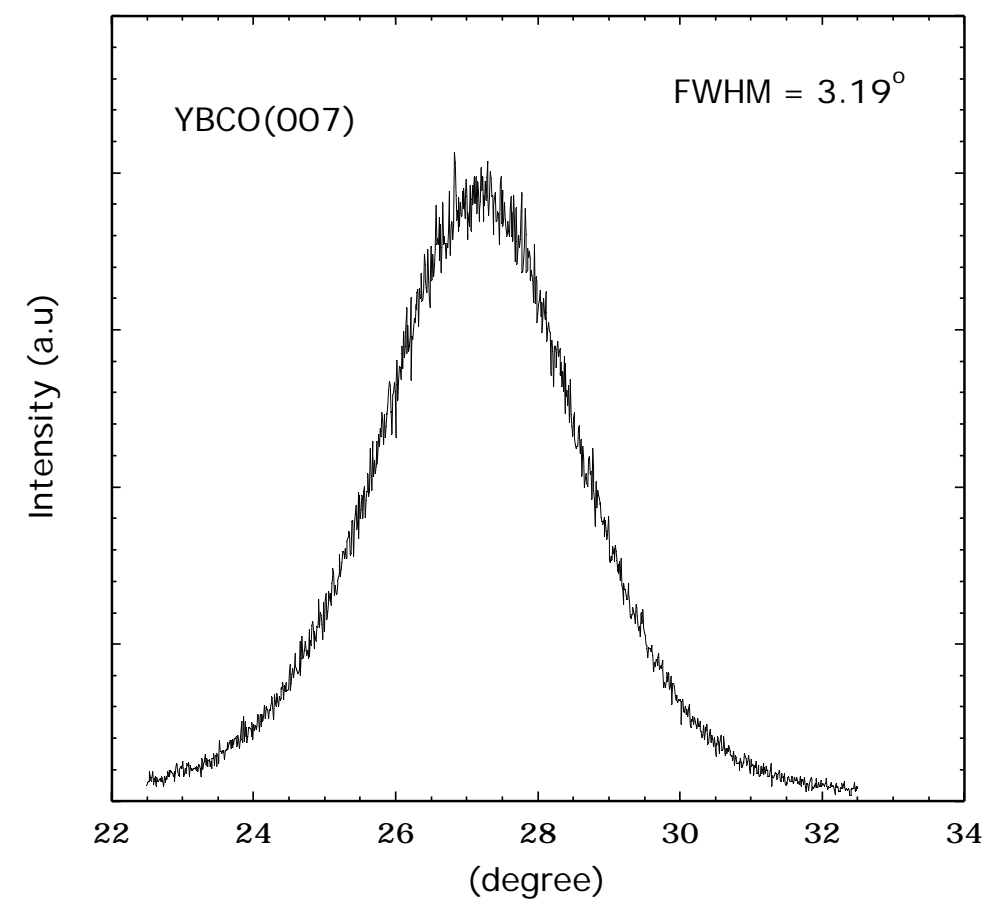

Fig. 3. X-ray $\omega$-scan for YBCO (007) planes on SRO buffered ISD-MgO substrate. 
The $\mathrm{T}_{\mathrm{c}}$ of $\mathrm{YBCO} / \mathrm{SRO} / \mathrm{ISD}-\mathrm{MgO} / \mathrm{YSZ} / \mathrm{HC}$ samples was measured by an inductive magnetization method in which the sample is placed between a primary and a secondary coil, and an alternating current is applied to the primary coil. A lock-in amplifier measures the voltage that the penetrating field produced in the secondary coil. After the samples were coated with $2 \mu \mathrm{m}$ of silver using electron beam evaporation and were re-oxygenated at $450^{\circ} \mathrm{C}$ in $1 \mathrm{~atm} \mathrm{O}_{2}$, their $\mathrm{J}_{\mathrm{c}}$ at $77 \mathrm{~K}$ was measured by a standard four-probe method. Figure 4 shows the inductive $\mathrm{T}_{\mathrm{c}}$ of a sample whose YBCO layer was deposited at $770^{\circ} \mathrm{C}$. This film had an onset $T_{c}$ of $89.2 \mathrm{~K}$ with a superconducting transition width of $0.8 \mathrm{~K}$. The sharpness of the transition suggests that the film was homogeneous. The sample, whose $\mathrm{YBCO}$ layer was $0.5 \mathrm{~cm}$ wide and 0.3 $\mu \mathrm{m}$ thick, had a transport $\mathrm{J}_{\mathrm{c}}$ of $6.2 \times 10^{5} \mathrm{~A} / \mathrm{cm}^{2}$ at $77 \mathrm{~K}$, as seen in Fig. 5 .

The results of this study are encouraging and indicate that SRO is a promising alternative to the YSZ and $\mathrm{CeO}_{2}$ buffer layers in the standard ISD architecture. Although we have produced higher $\mathrm{J}_{\mathrm{c}}$ values using the standard ISD architecture, the latest $\mathrm{J}_{\mathrm{c}}$ for SRO-buffered ISD-MgO on $\mathrm{HC}$ is significantly higher than the initial values $\left(0.03-0.10 \times 10^{5} \mathrm{~A} / \mathrm{cm}^{2}\right)$ reported for this architecture [2]. In addition, SRO-buffered ISD-MgO substrates routinely yield significantly sharper texture in the YBCO than is

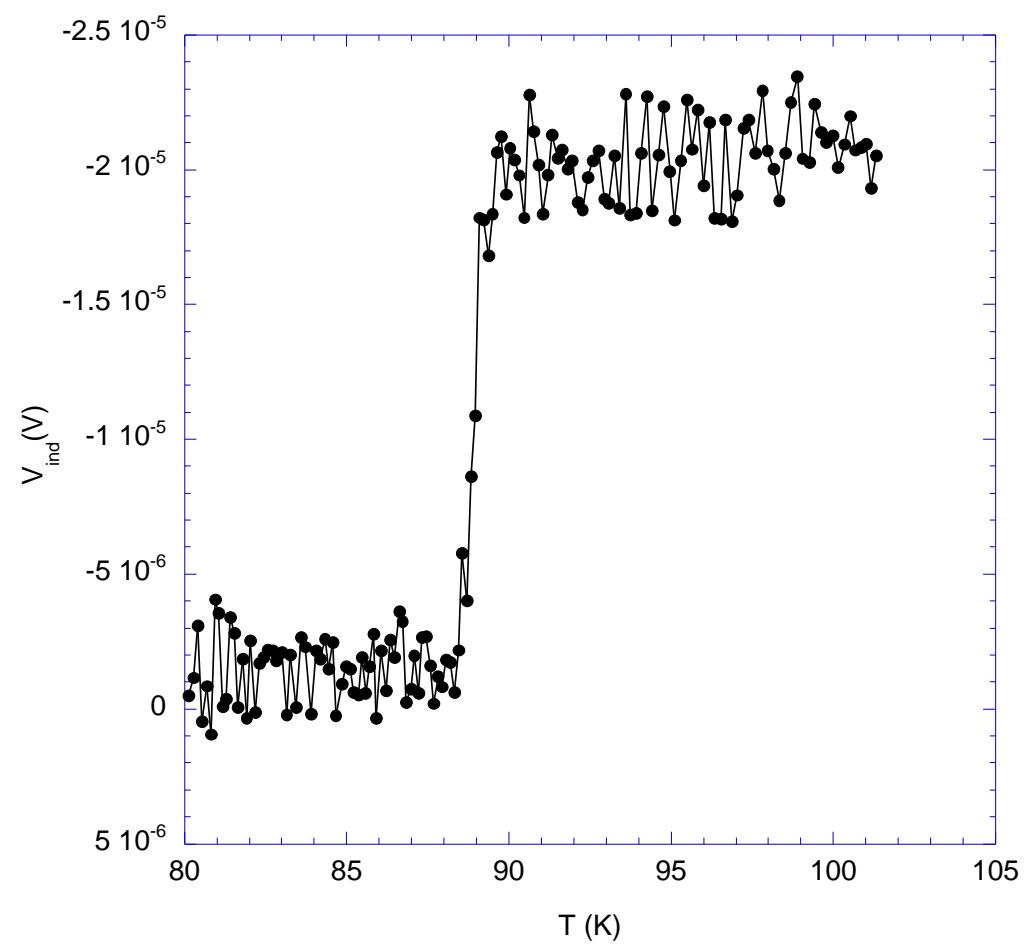

Fig. 4. Superconducting transition of YBCO film deposited on SRObuffered ISD-MgO on HC substrate. 


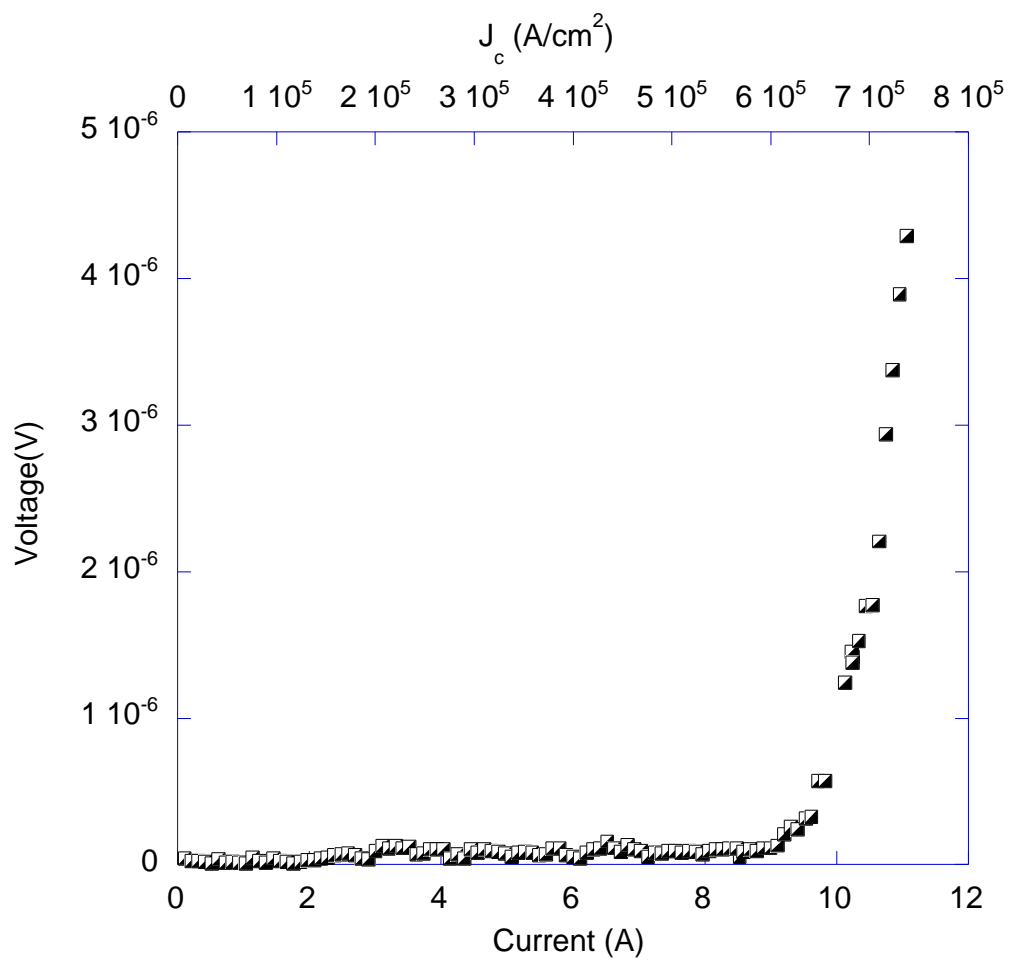

Fig. 5. Transport $J_{c}$ of YBCO film grown on SRO-buffered ISD$\mathrm{MgO}$ on HC substrate.

obtained with the standard ISD architecture. This enhanced texture suggests that higher $\mathrm{J}_{\mathrm{c}}$ might result from further optimization of the conditions for producing samples made with SRO.

\section{$\underline{\text { Raman Analysis of YBCO on SRO-Buffered ISD-MgO }}$}

Raman microscopy was used to characterize YBCO films deposited by PLD on $\mathrm{SRO} / \mathrm{HE}-\mathrm{MgO} / \mathrm{ISD}-\mathrm{MgO} / \mathrm{YSZ} / \mathrm{HC}$. Unless noted otherwise, the films (thickness $=0.3$ $\mu \mathrm{m}$ ) were produced at $770^{\circ} \mathrm{C}$ and $240 \mathrm{mtorr} \mathrm{O}_{2}$ using a laser pulse frequency of $8 \mathrm{~Hz}$. The Raman analysis was done with a Renishaw RM2000 Raman microscope in the $\mathrm{xx} / \mathrm{yy}$ configuration; a representative spectrum of the YBCO films is shown in Fig. 6 . All films contained small amounts of $\mathrm{CuO}$ (shown by the peak at $295 \mathrm{~cm}^{-1}$ ) and some cation disorder (seen by the broad peak at $580 \mathrm{~cm}^{-1}$ and a shift in the Ba line from the theoretical value of $118 \mathrm{~cm}^{-1}$ to $113 \mathrm{~cm}^{-1}$ ). The out-of-plane texture of the YBCO films (quantified by the $\mathrm{I}_{\mathrm{O}(4)} / \mathrm{I}_{\mathrm{O}(2+/ 3-)}$ intensity ratio) had an average value of 0.45 . Because the standard deviation of this ratio across the entire film's surface was very small for all samples (ranging from 0.05 to 0.09 for individual samples), we conclude that the $O(4)$ mode was generated by the ISD substrate tilt and not by the presence of random a-axis oriented YBCO grains. 


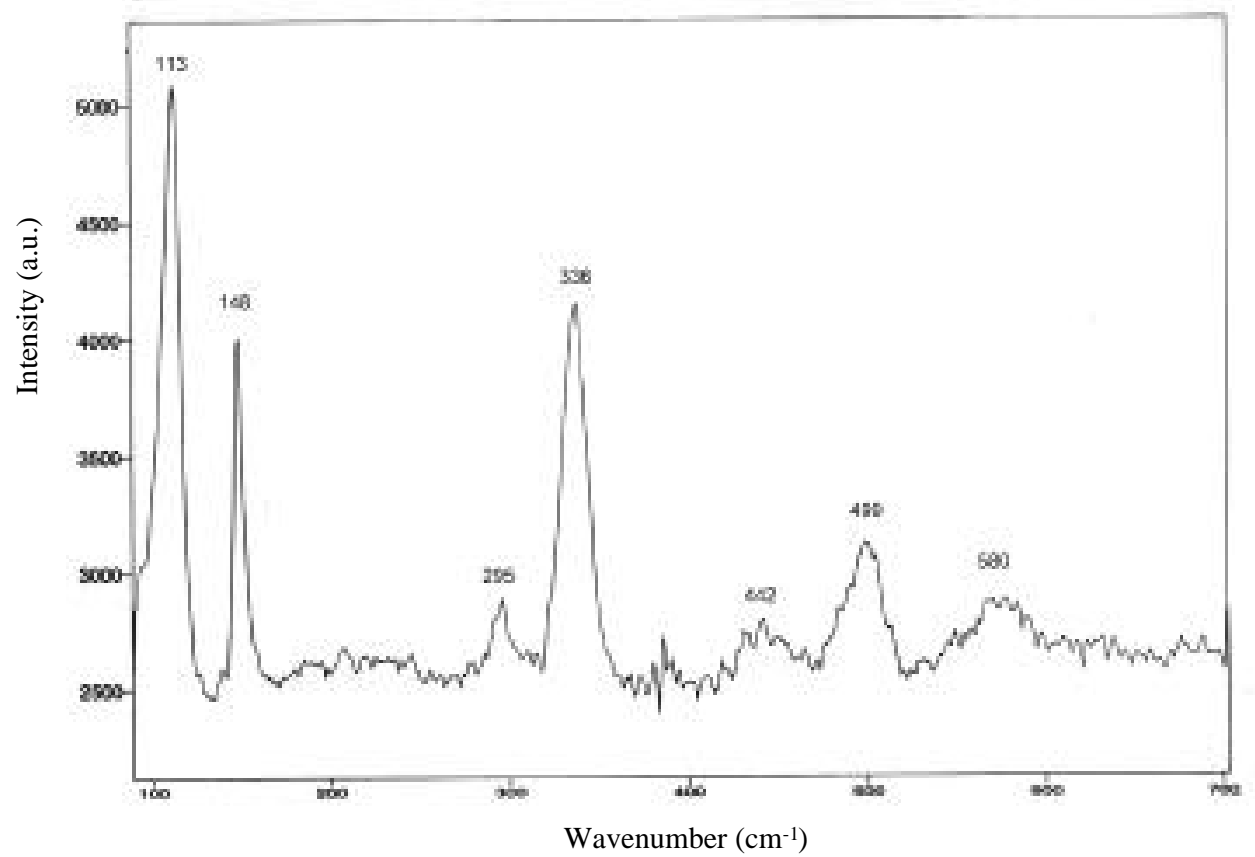

Fig. 6. Typical Raman spectrum of YBCO film deposited on SRO-buffered ISD$\mathrm{MgO}$ on HC substrate.

The structure of the YBCO in these films was orthorhombic, but the films appeared to be incompletely oxygenated. This observation was suggested by the positioning of the $\mathrm{Cu}(2)$ mode at $148 \mathrm{~cm}^{-1}$, instead of being centered at $150 \mathrm{~cm}^{-1}$ as in fully oxygenated samples. Also pointing to deficient oxygenation of the film, the peak corresponding to the out-of-phase bending of $\mathrm{O}(2)$ and $\mathrm{O}(3)$ atoms was shifted to values lower than $445 \mathrm{~cm}^{-1}$.

The Raman spectra of YBCO films produced at higher temperatures $\left(>770^{\circ} \mathrm{C}\right)$ had distinctive features: (a) two strong peaks at 239 and $632 \mathrm{~cm}^{-1}$, which are associated with the formation of $\mathrm{BaCuO}_{2}$, and (b) a very strong, broad peak at $580 \mathrm{~cm}^{-1}$, which indicates an increased cation disorder in the film. These results are consistent with our observation that the best superconducting properties on SRO-buffered ISD-MgO substrates are obtained at a deposition temperature of $770^{\circ} \mathrm{C}$.

\section{$\underline{\text { Raman Analysis of SRO Texture }}$}

In light of the promising results obtained with SRO-buffered ISD-MgO on HC, we are investigating whether Raman analysis can provide useful information regarding the structure of the SRO layer. SRO films with various thickness (100-400 nm) were deposited on $\mathrm{MgO}$ (100) single crystals over a range in deposition temperature (750$790^{\circ} \mathrm{C}$ ), and were analyzed by Raman spectroscopy to determine if a correlation exists 
between the Raman results and XRD measurements. The Raman spectra were collected by an Ar ion laser $(514.5 \mathrm{~nm})$ in $\mathrm{y}\left(\mathrm{x}^{\prime} \mathrm{x}^{\prime}\right) \mathrm{y}$ geometry.

SRO has an orthorhombic structure resulting from distortion of the ideal cubic perovskite structure, and belongs to the Pnma space group, $\mathrm{Z}=4$, with a total of 24 Raman-active phonon modes $\left(7 \mathrm{~A}_{\mathrm{g}}+5 \mathrm{~B}_{1 \mathrm{~g}}+7 \mathrm{~B}_{2 \mathrm{~g}}+5 \mathrm{~B}_{3 \mathrm{~g}}\right)$. The Raman spectra of the SRO films showed five bands: four strong lines at $212\left(\mathrm{~A}_{\mathrm{g}}\right), 240\left(\mathrm{~A}_{\mathrm{g}}\right), 375\left(\mathrm{~B}_{2 \mathrm{~g}}\right)$, and $400\left(\mathrm{~B}_{2 \mathrm{~g}}\right)$ $\mathrm{cm}^{-1}$ and a weak peak at $281 \mathrm{~cm}^{-1}\left(\mathrm{~A}_{\mathrm{g}}\right)$. The positions of the SRO peaks agree with values reported by Iliev et al. [4] for Raman measurements done at room temperature on oriented SRO thin films. Figure 7 shows a typical Raman spectrum from an SRO film deposited on a $\mathrm{MgO}$ (100) single-crystal substrate.

From calculations of the integrated intensities for various peaks in the SRO Raman spectra, we observed a direct correlation between the $\mathrm{I}_{212} / \mathrm{I}_{375}$ ratio and the in-plane texture of the film (determined from XRD $\phi$-scans of the (022) plane). Figures 8a and 8b illustrate this correlation. Figure 8a shows the dependence of the in-plane texture on SRO deposition temperature. When the deposition temperature was raised from 750 to $790^{\circ} \mathrm{C}$, the in-plane alignment of SRO improved and the FWHM for the $\phi$-scan decreased. Likewise, the $\mathrm{I}_{212} / \mathrm{I}_{375}$ ratio decreased as the deposition temperature increased. Figure $8 \mathrm{~b}$ plots the FWHM of SRO (022) $\phi$-scans from SRO films with

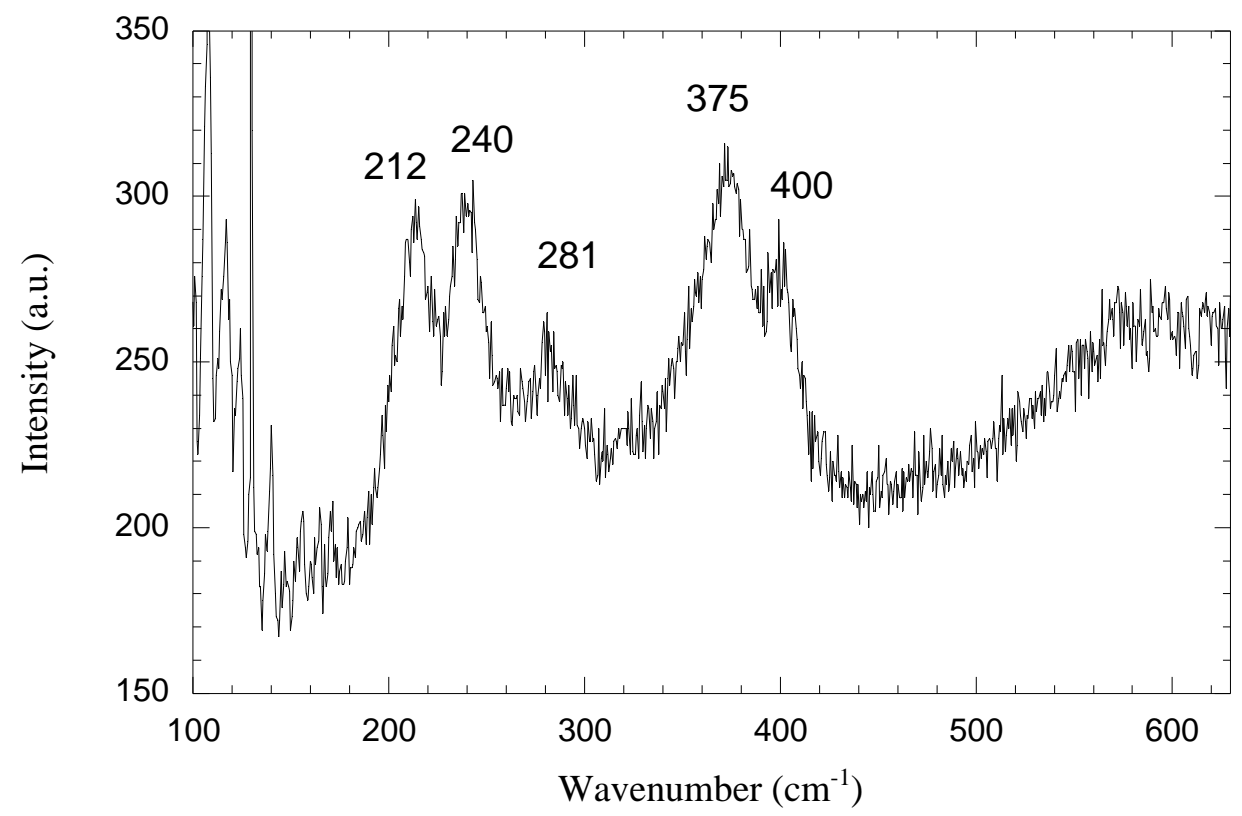

Fig. 7. Typical Raman spectrum of SRO film deposited on single-crystal $\mathrm{MgO}$ substrate. 


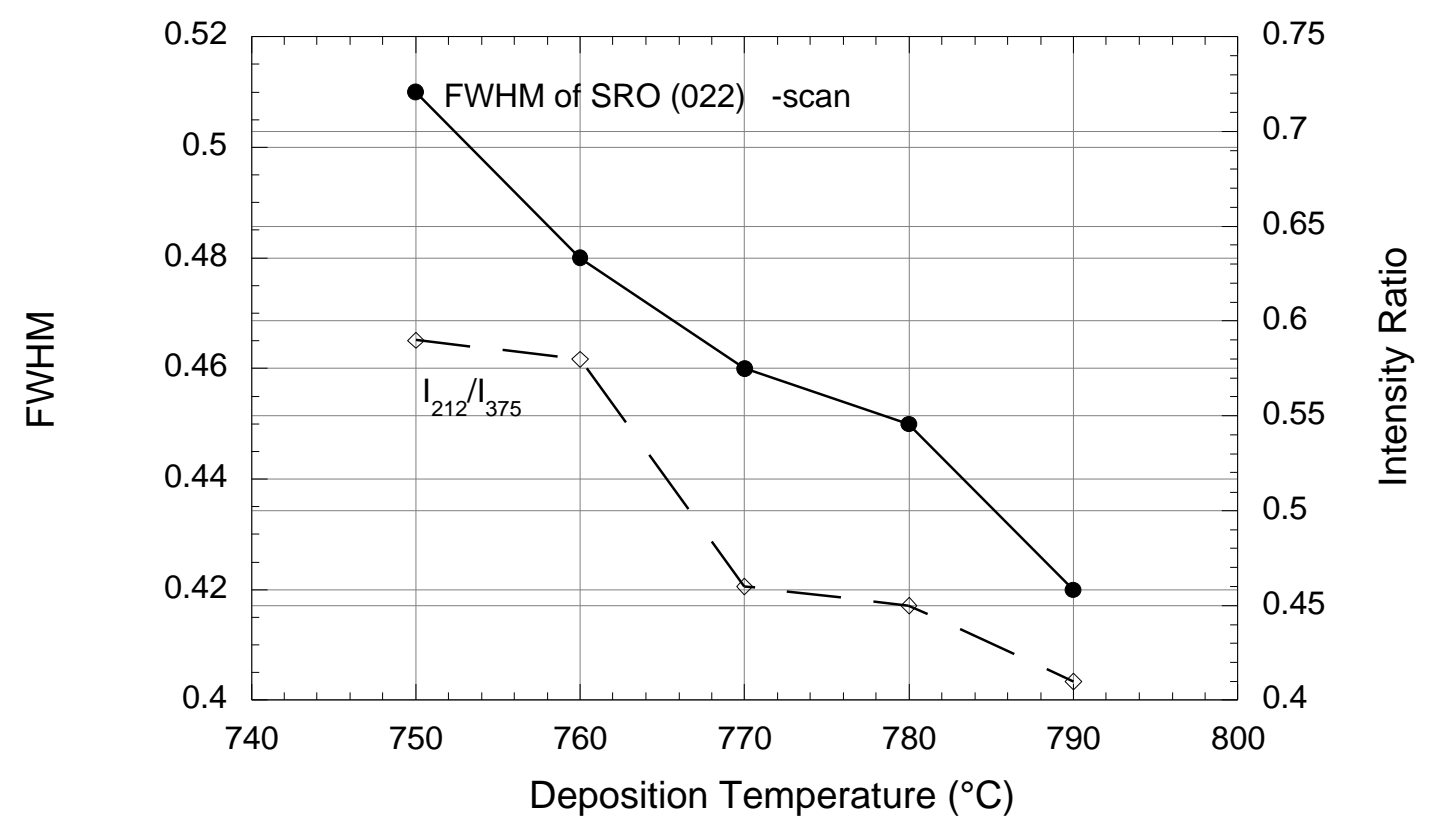

(a)

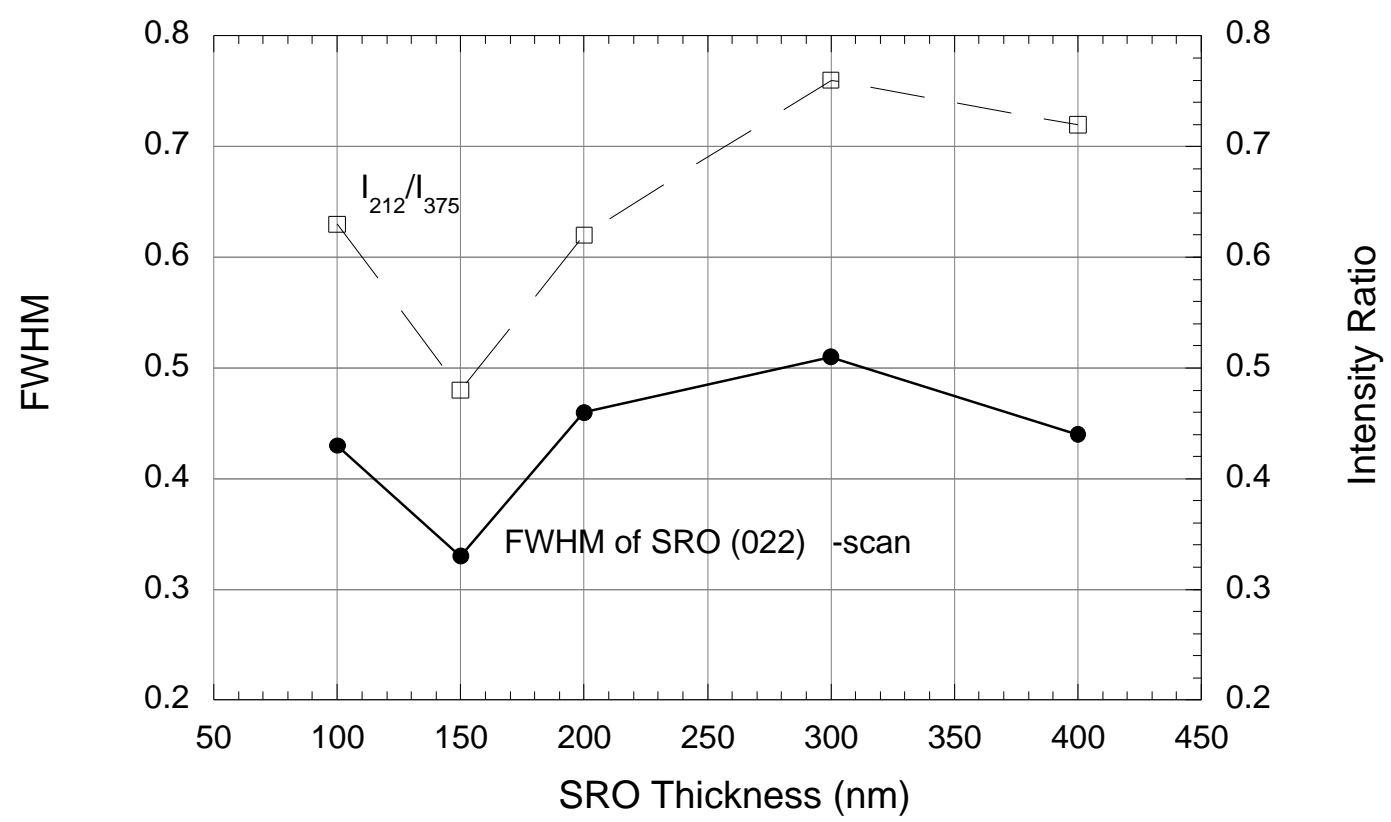

(b)

Fig. 8. Correlation between $I_{212} / I_{375}$ ratio from Raman analysis and in-plane texture measured by FWHM of SRO (022) ф-scans vs. (a) SRO deposition temperature and (b) SRO film thickness. 
various thickness along with the corresponding $\mathrm{I}_{212} / \mathrm{I}_{375}$ ratio. Although the results in Fig. $8 \mathrm{~b}$ show no correlation between film thickness and texture, the $\mathrm{I}_{212} / \mathrm{I}_{375}$ ratio and FWHM values were consistent, i.e., they followed the same trend.

Figures $9 \mathrm{a}$ and $9 \mathrm{~b}$ show another direct relationship between the $\mathrm{I}_{400} / \mathrm{I}_{375}$ ratio and out-of-plane texture (determined by the FWHM of SRO (020) $\omega$-scans). Figure 9a plots the FWHM of SRO (020) $\omega$-scans and the $\mathrm{I}_{400} / \mathrm{I}_{375}$ ratio versus the deposition temperature of SRO. The $\mathrm{I}_{400} / \mathrm{I}_{375}$ ratio and FWHM vary in the same way, their lowest values being obtained for the SRO film deposited at $770^{\circ} \mathrm{C}$. Figure $9 \mathrm{~b}$ shows that $\mathrm{I}_{400} / \mathrm{I}_{375}$ and FWHM also follow similar trends with thickness, even though there is no clear correlation between the out-of-plane texture and film thickness.

The results from this study indicate that Raman analysis might be used to evaluate the texture of SRO films, although the practical utility of the method is somewhat limited relative to XRD $\phi$ - and $\omega$-scans, which generally produce a more accurate quantitative measurement.

\section{$\underline{\text { Residual Stresses in Multilayered Coated Conductors }}$}

We previously estimated the residual stress in an ISD-MgO layer deposited on a HC substrate [2] by using Stoney's equation [1] with the measured change in curvature before and after deposition. Because the ISD-MgO layer was deposited at room temperature, the stress is believed to be intrinsic to the deposition process. Before applying Stoney's equation to analyze the residual stresses in more complex coated conductor structures, however, one must take into account the interaction between the various layers. To consider these interactions, we performed a 3-D finite element analysis (FEA) of the residual stresses in the layers of a multilayered coated conductor system. Specifically, the residual stresses were estimated by FEA for a coated conductor with the following configuration: $\mathrm{YBCO} / \mathrm{CeO}_{2} / \mathrm{YSZ} / \mathrm{HE}-\mathrm{MgO} / \mathrm{ISD}-\mathrm{MgO} / \mathrm{HC}$. The thickness of the HC substrate was assumed to be $150 \mu \mathrm{m}$ for the analysis. The thickness and deposition temperatures used in the analysis for the other layers are given in Table 1.

The multilayered coated conductor system was modeled as a rectangular geometry (10 $\mathrm{mm} \times 5 \mathrm{~mm})$. The HC substrate was treated as a 3-D deformable body, whereas all the other layers were considered as planar homogeneous shells (i.e., stress was assumed to be constant within each layer). Interactions arising from differences in the coefficient of thermal expansion and those arising from differences in elastic properties were both considered in computing the stresses in the different layers. The effects of intrinsic stresses developed during deposition and stress relaxation due to creep/plastic 


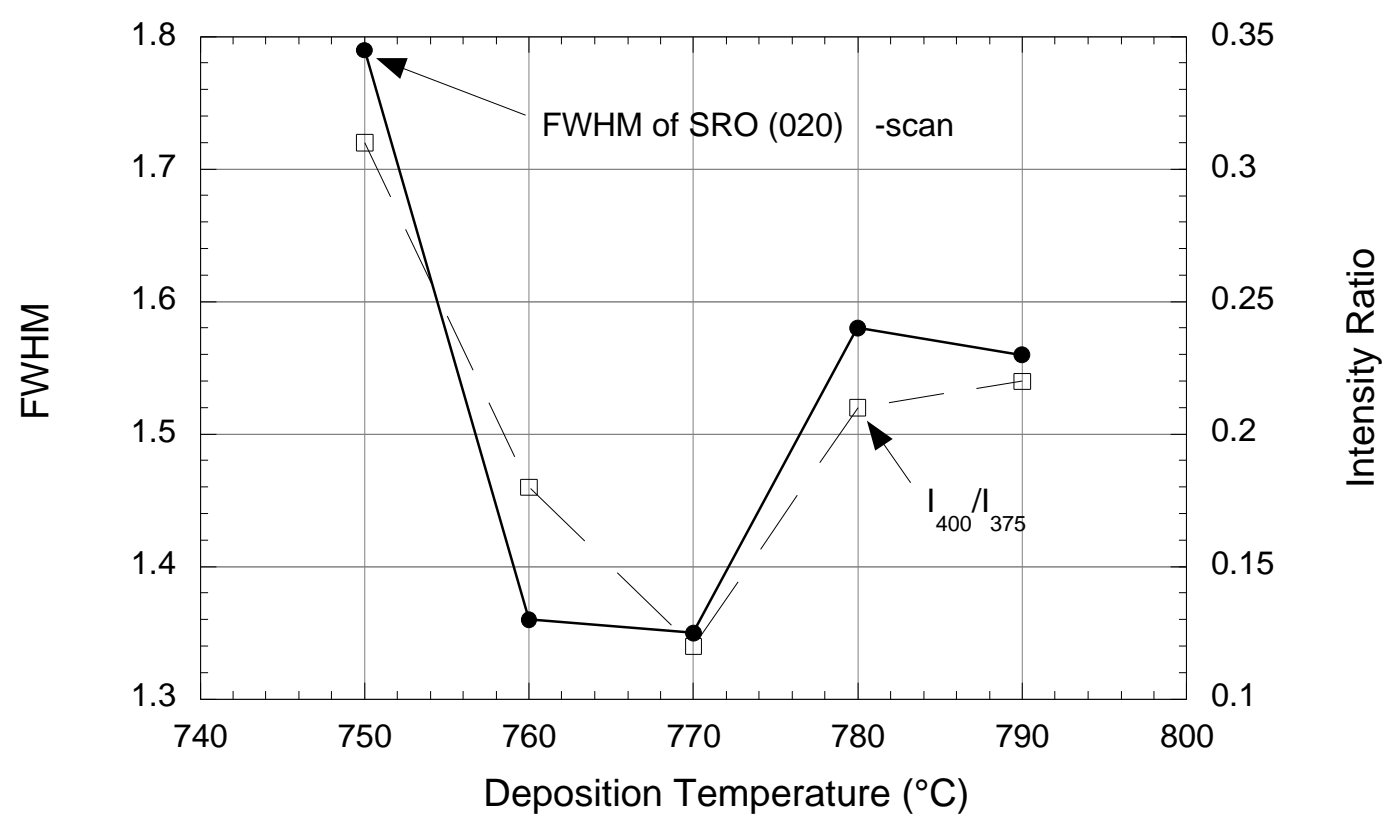

(a)

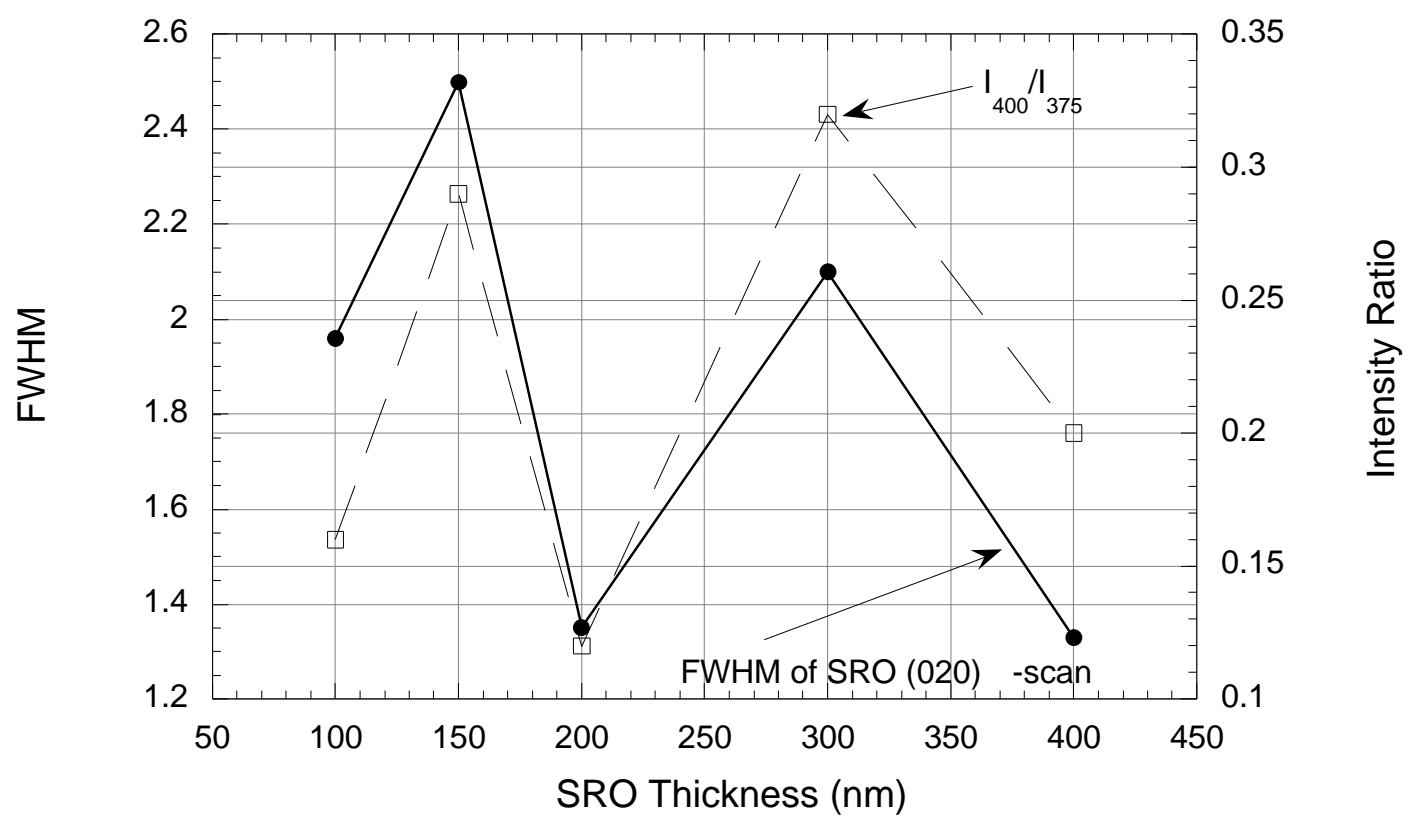

(b)

Fig. 9. Correlation between $I_{400} / I_{375}$ ratio from Raman analysis and out-of-plane texture measured by FWHM of SRO (020) $\omega$-scans vs. (a) SRO deposition temperature and (b) SRO film thickness. 
Table 1. Thickness and deposition temperature for different layers used in finite element modeling

\begin{tabular}{|c|c|c|}
\hline Layer & Thickness $(\mu \mathrm{m})$ & Deposition Temperature $\left({ }^{\circ} \mathrm{C}\right)$ \\
\hline ISD-MgO & 2 & Room temperature \\
\hline $\mathrm{HE}-\mathrm{MgO}$ & 0.5 & 700 \\
\hline $\mathrm{YSZ}$ & 0.15 & 800 \\
\hline $\mathrm{CeO}_{2}$ & 0.01 & 800 \\
\hline $\mathrm{YBCO}$ & 0.3 & 760 \\
\hline
\end{tabular}

deformation were ignored in the analysis. The simulations were done using ABAQUS standard finite element software. The stresses were computed in the direction parallel to the plane of the coated layers.

Figure 10 shows the residual stresses that were computed by FEA for the different layers of the coated conductor. As shown in the figure, the stress in the YBCO layer is $\approx 135 \mathrm{MPa}$. For each layer of the conductor, Fig. 11 compares the residual stress

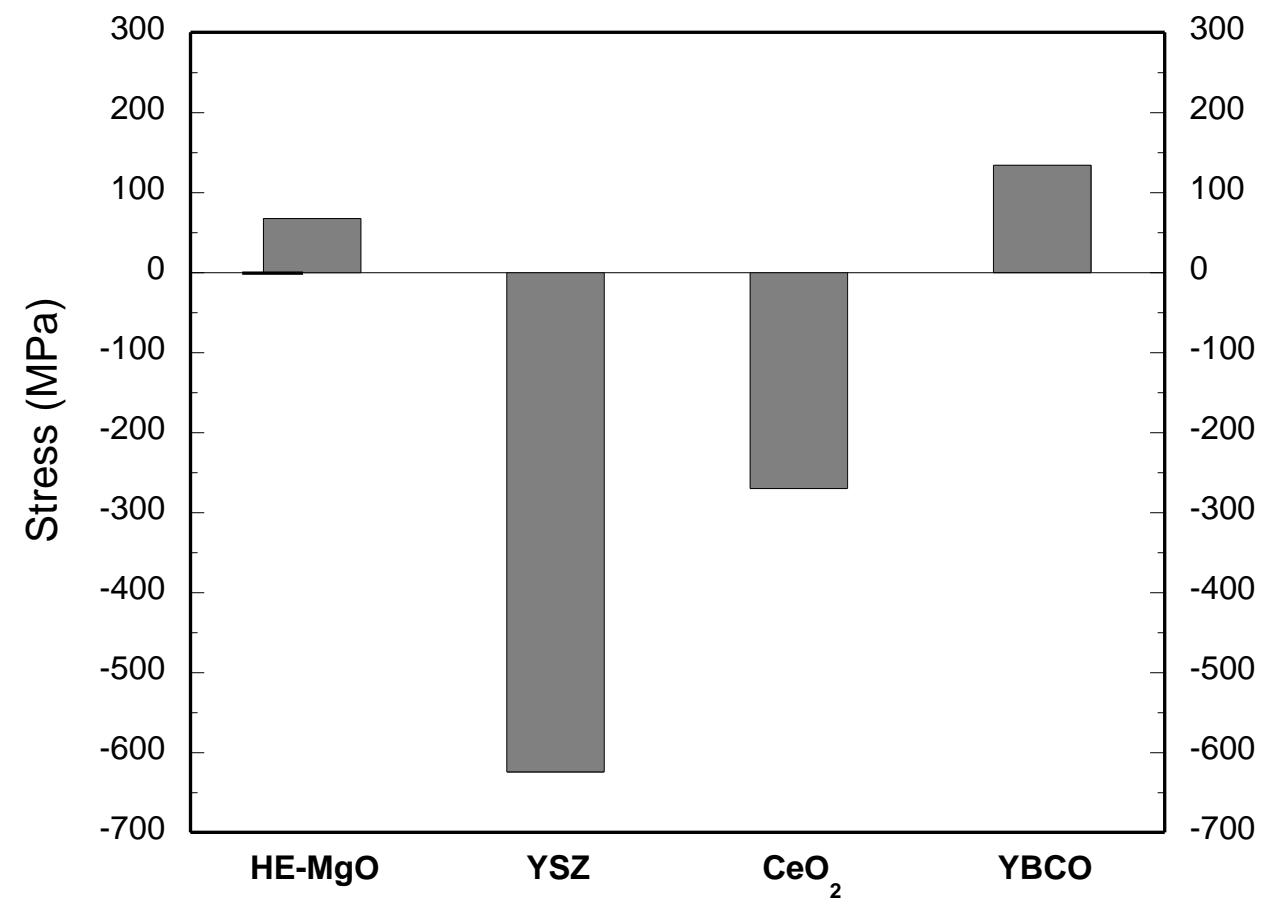

Fig. 10. Residual stresses estimated by FEA for various layers of YBCO coated conductor: $Y B C \mathrm{BC} / \mathrm{CeO}_{2} / \mathrm{YSZ} / \mathrm{HE}-\mathrm{MgO} / \mathrm{ISD}-\mathrm{MgO} / \mathrm{HC}$. 


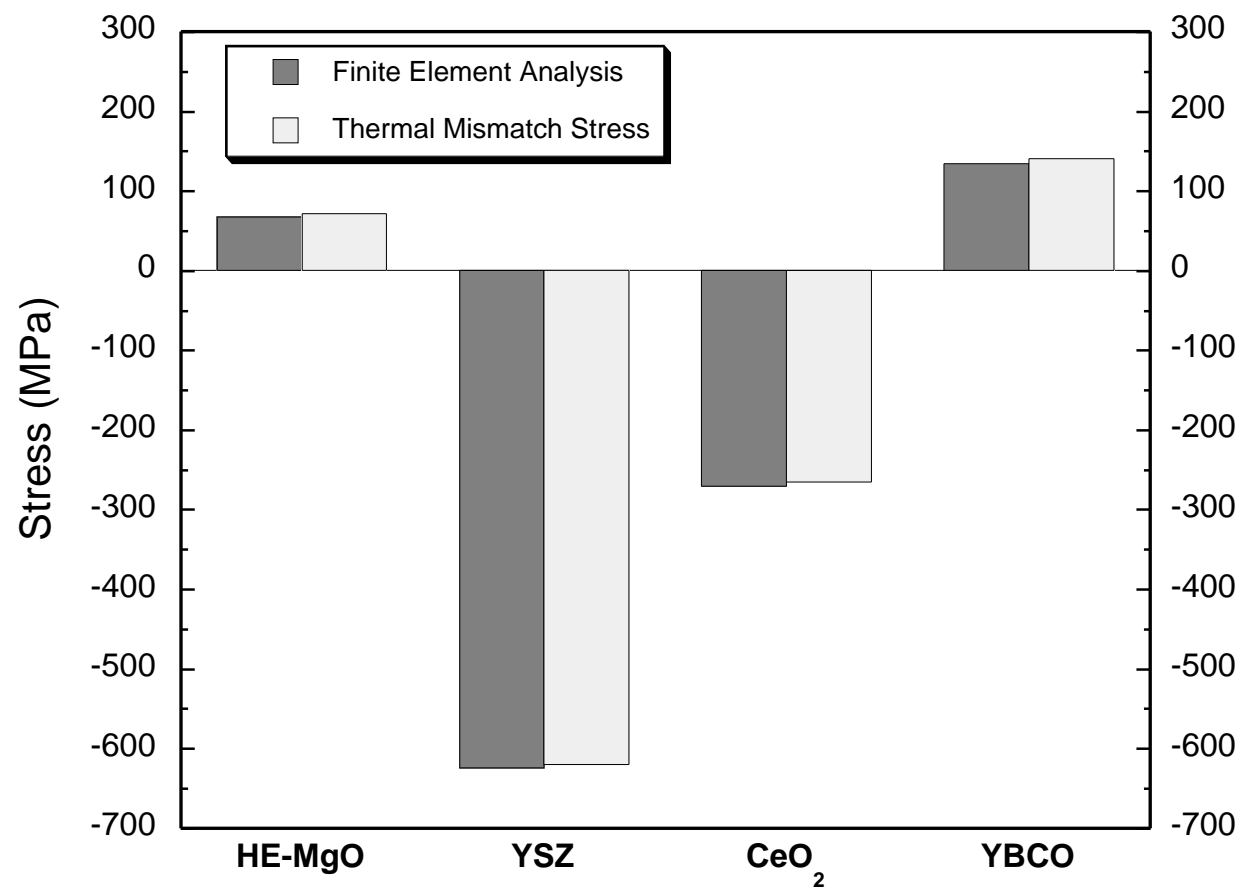

Fig. 11. Comparison of residual stresses estimated by FEA with thermal mismatch stresses obtained by analytical calculations for layers of $Y B C O$ coated conductor: $\quad Y B C O / \mathrm{CeO}_{2} / Y S Z / H E-M g O / I S D-$ $\mathrm{MgO} / \mathrm{HC}$.

estimated by FEA with the analytically calculated thermal mismatch stress. Note that the stresses estimated by FEA (which considers the interaction between layers) agree well with those obtained by analytical calculation (which ignores the interaction between layers). This finding suggests that the effect from the interactions between layers is insignificant; therefore, using Stoney's equation with the measured change in curvature should provide reasonable estimates of the residual stresses in the individual layers of complex coated conductors. Further finite element modeling will be done to estimate the curvature change that is expected for the different layers due to residual stresses. A comparison of these estimated curvatures with those measured by optical interferometry will provide guidance on the validity of our experimental technique and FEA modeling. 


\section{References}

[1]. G. G. Stoney, Proc. of the Royal Society, London, Series A 82, 172 (1909).

[2]. Argonne National Laboratory, Practical Superconductor Development for Electrical Power Application, Quarterly Report for Jan.-Mar., 2003.

[3]. Argonne National Laboratory, Practical Superconductor Development for Electrical Power Application, Quarterly Report for Jul.-Sept., 2003.

[4]. M. N. Iliev, A. P. Litvinchuk, H. -G. Lee, C. L. Chen, M. L. Dezaneti, C. W. Chu, V. G. Ivanov, M. V. Abrashev, and V. N. Popov, Phys. Rev. B, 59, 364 (1999).

\section{Interactions}

Balu Balachandran presented a paper on inclined substrate deposition at the Annual Meeting of the Electrochemical Society, Oct. 16, 2003, Orlando, FL.

Balu Balachandran attended the post Peer Review Meeting in Washington, D.C., on Oct. 21, 2003.

Balu Balachandran attended the 11 th U.S-Japan Workshop on Superconductors, Nov. 1-2, 2003, Kanagawa, Japan.

Victor Maroni and Dean Miller attended the Materials Research Society Fall Meeting, Dec. 1-4, 2003, Boston, MA.

Victor Maroni attended the Wire Development Group meeting at American Superconductor Corp., Dec. 4-5, 2003, Westborough, MA. Other participants included ANL, AMSC, LANL, and UWM at session on $1^{\text {st }}$ generation conductors plus ORNL at the session on $2^{\text {nd }}$ generation conductors.

Balu Balachandran attended the Coalition for Commercial Application of Superconductivity (CCAS), Dec. 16, 003, New York, NY.

\section{Publications and Presentations}

\section{Published/Submitted}

K. Venkataraman, A. J. Kropf, C. U. Segre (Ill. Inst. of Tech.), Q. X. Jia (LANL), A. Goyal (ORNL), B. W. Kang (ORNL), S. Chattopadhyay (Ill. Inst. of Tech.), H. You, V. A. 
Maroni, Detection of Interfacial Strain and Phase Separation in $\mathrm{MBa}_{2} \mathrm{Cu}_{3} \mathrm{O}_{7-\mathrm{x}}$ Thin Films using Raman Spectroscopy and X-Ray Diffraction Space Mapping, Physica C 402, 1-16 (2004).

V. K. Vlasko-Vlasov, H. Claus, U. Welp, K. E. Gray (MSD), B. Ma, and U. Balachandran, Improving Ratio of the Grain Boundary and Bulk Critical Currents in $\mathrm{YBa}_{2} \mathrm{Cu}_{3} \mathrm{O}_{7-\delta}$ Films, Appl. Phys. Lett., Vol. 84, No. 2 (2004) 242-244.

U. Balachandran, B. Ma, B. L. Fisher, R. E. Koritala, and D. E. Miller, Fabrication of YBCO-Coated Conductors by Inclined Substrate Deposition, Invited extended abstract presented at the $11^{\text {th }}$ U.S.-Japan Workshop on High- $\mathrm{T}_{\mathrm{c}}$ Superconductors, Kanagawa, Japan, Oct. 31-Nov. 2, 2003.

B. Ma, R. E. Koritala, B. L. Fisher, K. K. Uprety, R. Baurceanu, S. E. Dorris, D. J. Miller, P. Berghuis, K. E. Gray, and U. Balachandran, High Critical Current Density of YBCO Coated Conductors Fabricated by Inclined Substrate Deposition, Submitted to Physica C (October 2003).

K. K. Uprety, B. Ma, R. E. Koritala, R. M. Baurceanu, T. P. Weber, B. L. Fisher, S. E. Dorris, R. A. Erck, V. A. Maroni, and U. Balachandran, Growth of YBCO Film on $\mathrm{SrRuO}_{3}$-buffered $\mathrm{MgO}$ Substrate, Submitted to Superconductor Science and Technology (Nov. 2003).

P. S. Shankar, S. H. Majumdar, S. Majumdar, and J. P. Singh, Finite Element Modeling of Residual Stresses in Multilayered Coated Conductors, Abstract to be presented at the 106 ${ }^{\text {th }}$ Ann. Mtg. of the American Ceramic Society, Indianapolis, April 18-21, 2004.

Patents: 2000-2003

Fabrication of High Temperature Superconductors

Uthamalingam Balachandran, Stephen E. Dorris, , and

U.S. Patent No. 6,579,360 (June 17, 2003).

Metallic Substrates for High-Temperature Superconductors

T. Truchan, D. Miller, K. C. Goretta, U. Balachandran, and R. Foley (U. of IL)

U.S. Patent No. 6,455,166 (Sept. 24, 2002).

Method for Preparing High-Temperature Superconductor

Uthamalingam Balachandran and Michael P. Chudzik

U.S. Patent No. 6,361,598 (March 26, 2002). 
Shielded High- $\mathrm{T}_{\mathrm{C}}$ BSCCO Tapes or Wires for High-Field Applications Uthamalingam Balachandran, Milan Lelovic, and Nicholas G. Eror

U.S. Patent No. 6,252,096 (June 26, 2001); U.S. Patent 6,466,805 (Oct. 15, 2002).

Thermomechanical Means to Improve Critical Current Density of BSCCO Tapes Uthamalingam Balachandran, Roger B. Poeppel, Pradeep Haldar (IGC), and Lesizek Motowidlo (IGC), U.S. Patent 6,240,619 (June 5, 2001).

Method of Manufacturing a High-Temperature Superconductor with Improved Transport Properties Uthamalingam Balachandran, Richard Siegel, and Thomas Askew U.S. Patent No. 6,191,075 (February 20, 2001).

Bearing Design for Flywheel Energy Storage Using High- $\mathrm{T}_{\mathrm{c}}$ Superconductors John R. Hull and Thomas M. Mulcahy U.S. Patent No. 6,153,958 (Nov. 28, 2000).

Method and Apparatus for Measuring Gravitational Acceleration Utilizing a HighTemperature Superconducting Bearing John R. Hull

U.S. Patent 6,079,267 (June 27, 2000).

Improvements in Levitation Pressure and Friction Losses in Superconducting Bearings, John R. Hull

U.S. Patent 6,175,175 (January 16, 2001).

Trapped Field Internal Dipole Superconducting Motor/Generator John R. Hull

U.S. Patent 6,169,352 (January 2, 2001).

Reluctance Apparatus for Flywheel Energy Storage John R. Hull U.S. Patent 6,097,118 (August 1, 2000).

Large Area Bulk Superconductors

Dean J. Miller and Michael B. Field

U.S. Patent 6,410,487 (June 25, 2002). 